thymoma), and $10 \%$ to $15 \%$ of patients with MG are found to have a thymoma. ${ }^{1}$ An autoimmune mechanism dependant on $\mathrm{CD}^{+}{ }^{+} \mathrm{T}$ lymphocytes is suspected to be responsible for the GCM, and immunosuppressive therapy has been used to delay transplantation. ${ }^{3}$ Median survival or time to heart transplantation of 5 to 6 months had been reported in GCM. ${ }^{3}$ Ventricular assistance as a bridge to heart transplantation was reported in patients who had terminal heart failure within a week. ${ }^{4}$ Our patient, like the one reported by Glennon and colleagues, ${ }^{2}$ presented in shock within hours after the onset of symptoms, despite maximal medical treatment. Both patients had no sign of active myocarditis before the thymoma resection, and the operation might have in some way triggered the disease. This very aggressive form of the disease after a thymoma resection did not allow a premortem diagnosis and thus the administration of appropriate immunotherapy or a ventricular support device as a bridge to heart transplantation. ${ }^{3,4}$ Transplantation remains the treatment of choice in the absence of recovery of myocardial function with immunosuppressive agents, although the disease is known to recur in the transplanted heart. ${ }^{3}$ Marelli and coworkers ${ }^{4}$ reported one case of recovery of myocardial function with biventricular assistance for 10 days and immunosuppressive therapy with a follow-up of 3 years. Even if GCM appears to be a very rare disease, this diagnosis should be considered in patients who experience rapidly progressive heart failure after thymoma resection. Although the possibility of massive pulmonary embolism or myocardial infarction should not be ignored, early myocardial biopsy might lead to the diagnosis. Appropriate immunosuppressive therapy and circulatory support as a bridge to transplantation can be administrated.

\section{References}

1. Drachman DB. Myasthenia gravis. N Engl J Med. 1994;330:1797-810.

2. Glennon PE, Petersen ME, Sheppard MN. Fatal giant cell myocarditis after resection of thymoma. Heart. 1996;75:531-2.

3. Cooper LT, Berry GJ, Shabetai R. Idiopathic giant cell myocarditisnatural history and treatment. Multicenter Giant Cell Myocarditis Study Group Investigators. N Engl J Med.1997;336:1860-6.

4. Marelli D, Kermani R, Bresson J, Fishbein MC, Hamilton M, Moriguchi J, et al. Support with the BVS 5000 assist device during treatment of acute giant-cell myocarditis. Tex Heart Inst J. 2003;30:50-6.

\title{
Using Surgicel to buttress the staple line in lung volume reduction surgery for chronic obstructive pulmonary disease
}

Jang-Ming Lee, MD, PhD, Jen-Deh Pan, MD, Wei-Cheng Lin, MD, and Yung-Chie Lee, MD, PhD, Taipei, Taiwan

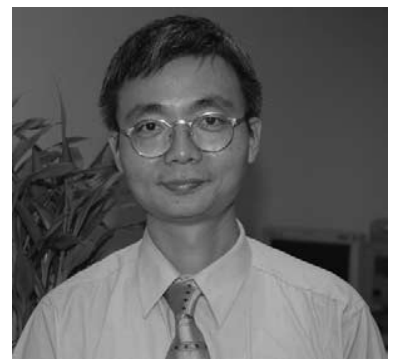

Dr W. Lee
A lthough effective for palliating the symptoms of chronic obstructive pulmonary disease (COPD), lung volume reduction surgery for COPD is highly vulnerable to postoperative major or persistent air leakage. ${ }^{1}$ Staple line reinforcement has been developed to prevent this complication, including using polyglycolic acid, ${ }^{2}$ bovine pericardial strips, ${ }^{3}$ or autologous parietal pleura. ${ }^{4}$ These materials either carry a high $\operatorname{cost}^{2,3}$ or take a substantial amount of time for preparation. ${ }^{4} \mathrm{~A}$ low-cost and easily available material for staple

\footnotetext{
From the Department of Surgery, National Taiwan University Hospital, Taipei, Taiwan.

Received for publication Aug 2, 2005; accepted for publication Sept 9, 2005.

Address for reprints: Yung-Chie Lee, MD, PhD, Department of Surgery, National Taiwan University Hospital, Taipei, Taiwan, Republic of China. 7, Chung-Shang South Rd, Taipei, Taiwan (Email: wuj@ha.mc.ntu.edu.tw).

J Thorac Cardiovasc Surg 2006;131:497-8

$0022-5223 / \$ 32.00$

Copyright $\odot 2006$ by The American Association for Thoracic Surgery

doi:10.1016/j.jtcvs.2005.09.039
}

buttressing is needed to facilitate its clinical application. We report a new technique using oxidized regenerated cellulose (Surgicel, Johnson \& Johnson) for lung volume reduction surgery for COPD.

\section{Clinical Summary}

Patient 1. A 72-year-old man with COPD complained of progressive exertional dyspnea unresponsive to bronchodilator treatment. He had left pneumothorax and received a thoracoscopic wedge resection on the pulmonary left upper lobe 4 years ago. Chest computed tomography revealed diffuse emphysematous change of the bilateral lung, especially in the right middle lobe. For intractable dyspnea, video-assisted thoracic surgery for lung volume reduction surgery on the right lung was arranged. About $30 \%$ of the pulmonary right upper lobe at the apex and 50\% of the right middle lobe at the basal portion was resected with a continuous staple line (Figure 1, B, C, and D). Before the lung resection, a strip of Surgicel, $4 \times 8 \mathrm{~cm}$, was tied on each site of the staple (Figure 1, $A$ ). The working port on the anterior axillary line of the fourth intercostal space was enlarged to $3 \mathrm{~cm}$ to prevent dislocation of fixed Surgicel during staple introduction. A total of 7 sets of Endo-GIA, $60 \times 4.8 \mathrm{~mm}$, and 2 sets of Endo-GIA, $45 \times 4.8$ $\mathrm{mm}$, staples (Tyco Health Care, US Surgical) were used during the operation. It took 2 hours for the entire surgical procedure. The 


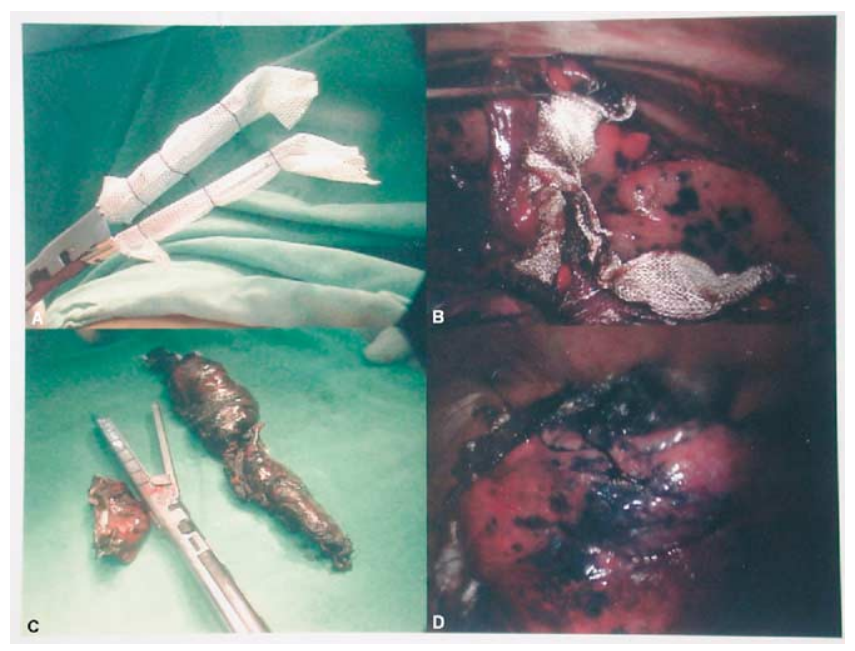

Figure 1. A, Surgicel tied on each site of the staple. B, Lung specimens, $15 \times 4$ and $5 \times 3 \mathrm{~cm}$, were excised from the right upper lobe and right middle lobe, respectively. C, Lung surface after resection (before saline pleural irrigation). D, Lung surface after resection (after saline pleural irrigation).

patient was extubated the day after the operation, with no air leakage found from the chest tube. The chest tube was removed 3 days later, and the patient was discharged 7 days after the operation.

Patient 2. A 56-year-old man with bullous emphysema had exertional dyspnea for 10 years. He had an episode of right tension pneumothorax before admission. He underwent endotracheal intubation and right chest tube thoracostomy in our emergency department for pneumothorax-induced respiratory failure. Chest computed tomography disclosed diffuse pulmonary emphysema with multiple small- to median-sized bullae in the bilateral lungs, especially in the right middle and lower lobes, and 2 huge bullae of $13 \mathrm{~cm}$ in diameter in the right lower lobe. Lung volume reduction surgery with bullectomy was suggested after he was weaned from a ventilator. During the operation, a thoracotomy through the seventh intercostal space was created for precise excision of the multiple lesions. Part of the pulmonary right upper and lower lobes with the most evident bullous formations was resected with 5 and 2 sets of GIA $90 \times 4.8-\mathrm{mm}$ and $50 \times 4.8-\mathrm{mm}$ staples (Tyco Health Care, US Surgical), respectively. Before staple application, one strip of Surgicel was tied on each side of the staple to buttress the staple line, as previously described. The surgical procedure took 2 hours and 30 minutes in total. The patient was extubated on the day of the operation. Minimal air leakage was noted from the chest tube after the operation, and the tube was removed 6 days after the operation, the same day as patient discharge.

\section{Discussion}

The oxidized cellulose compound Surgicel is currently indicated for hemostasis during surgical intervention. In pigs Surgicel coverage with local electroablation can significantly decrease air leakage from pleural tears. ${ }^{5}$ Our preliminary experience demonstrated that using Surgicel to buttress the staple line can effectively prevent postoperative air leakage after lung volume reduction surgery either in open or thoracoscopic procedures. Only a few minutes are required to attach it to the staple. The fixed Surgicel did not interfere with the staple application during lung resection. However, to avoid dislocation of the Surgicel fixed in the staple, we suggest a slight enlargement to the working port for staple application during the video-assisted thoracic surgery procedure. In contrast to other expensive buttress materials, Surgicel is commonly used in the operating theater, with a cost less than $5 \%$ of the bovine pericardium used in this country. Further studies examining efficacy and safety are necessary.

\section{References}

1. Cooper JD, Patterson GA, Sundaresan RS, Trulock EP, Yusen RD, Pohl MS, et al. Results of 150 consecutive bilateral lung volume reduction procedures in patients with severe emphysema. $J$ Thorac Cardiovasc Surg. 1996;112:1319-30.

2. Kawamura M, Kase K, Sawafuji M, Watanabe M, Horinouchi H, Kobayashi K. Staple-line reinforcement with a new type of polyglycolic acid felt. Surg Laparosc Endosc Percutan Tech. 2001;11:43-6.

3. Cooper JD. Technique to reduce air leaks after resection of emphysematous lung. Ann Thorac Surg. 1994;57:1038-9.

4. Lee YC, Chang YL, Chen CW, Chien NC, Huang PM. Use of autologous pleural flap buttress in thoracoscopic lung volume reduction surgery. J Thorac Cardiovasc Surg. 2003;126:298-9.

5. Luh SP, Chou HH, Tsai TP, Chen JY, Chou MC, Wang YH, et al. Effect of Surgicel coverage with topical electrocauterization for preventing and sealing pulmonary air leakage. Int Surg. 2004;89:190-4. 